\title{
Single-center experience and evolution of technique with the E-vita Open prosthesis.
}

\author{
Luis Maroto ${ }^{1}$, Manuel Carnero ${ }^{1}$, Francisco Cobiella ${ }^{1}$, Rosa Beltrao ${ }^{1}$, Enrique Villagrán ${ }^{1}$, \\ Fernando Reguillo ${ }^{1}$, and Daniel Pérez-Camargo ${ }^{1}$ \\ ${ }^{1}$ Hospital Clínico San Carlos
}

June 2,2020

\begin{abstract}
Background: We report our experience in aortic arch repair with the E-vita Open hybrid prosthesis and describe the changes in our technique over time. Methods: Between October 2013 and December 2019, 56 patients underwent a total aortic arch replacement with the E-vita Open hybrid prosthesis. Main indications were thoracic aorta aneurysm $(\mathrm{n}=27)$ and acute type A aortic dissection $(n=18)$. We analyze the technique and results in the overall series, and compare both between our early (Group I, 25 patients) and late experience (Group II, 31 patients). Results: Overall in-hospital mortality was $7.1 \%$ (4), and permanent stroke and spinal cord injury were $3.6 \%$ and $1.8 \%$ respectively. 15 patients $(26.8 \%)$ underwent a planned second procedure on the distal aorta: 13 endovascular, 1 open and 1 hybrid. Survival at 1 and 3 years was $90.7 \%$ and $80.7 \%$. Group II included more patients with acute dissection ( $45.2 \%$ vs $16 \%, \mathrm{p}=0.02)$, a higher rate of bilateral cerebral perfusion ( $100 \%$ vs $64 \%, \mathrm{p}<0.001)$, left subclavian artery perfusion during lower body circulatory arrest ( $87.1 \%$ vs $0 \%$, p $<0.001)$, early reperfusion ( $96.8 \%$ vs $40 \%, \mathrm{p}<0.001)$, and zone $0-2$ distal anastomosis ( $100 \%$ vs $72 \%, \mathrm{p}=0.02)$. In-hospital mortality $(3.2 \%$ vs $12 \%)$ and permanent stroke $(0 \%$ vs $8 \%$ ) tended to be lower in Group II. Conclusions: Total arch replacement with E-vita Open hybrid prosthesis in complex thoracic aorta disease is safe. One-stage treatment is feasible when pathology does not extend beyond the proximal descending thoracic aorta. In any case, it facilitates subsequent procedures on distal aorta if needed.
\end{abstract}

\section{Introduction}

Surgical treatment of extensive thoracic aortic disease usually implies either an aggressive one-stage procedure using bilateral anterior thoracotomy and transverse sternotomy ${ }^{1}$ or a two-step procedure ${ }^{2}$, both with high morbidity and mortality. The frozen elephant trunk (FET) technique with hybrid prostheses was developed to treat in a one-stage procedure and through median sternotomy the ascending aorta, aortic arch and proximal descending aorta. In addition, it facilitates subsequent procedures on distal aorta by endovascular, open or hybrid techniques ${ }^{3-5}$ if needed.

This study describes our experience with the E-vita Open hybrid prosthesis and the changes of the technique between 2013 and 2019.

\section{Materials and Methods}

\section{Patients}

This retrospective study was approved by our local ethics committee. Data was collected prospectively in our institutional database. From October 2013 to December 2019, 56 consecutive patients underwent a complete aortic arch replacement using the E-vita Open hybrid prosthesis. All the procedures were performed by two experienced surgeons. Main underlying diseases were degenerative aneurysm $(\mathrm{n}=27)$ and type A acute aortic dissection $(\mathrm{n}=18)$. Patients characteristics are presented in Table 1. 
As we gained experience (Figure 1), indications expanded to more complex diseases, and the technique was standardized. We compared the surgical technique and operative results between our early (Group I, October 2013-December 2017, n=25) and late experience (Group II, January 2018-December 2019, n=31).

\section{Surgical technique}

All operations were performed under general anesthesia and through median sternotomy. Patients were monitorized with transesophageal echocardiography, bilateral cerebral saturation with near infrared spectroscopy and three arterial lines (both radial arteries and one femoral artery). We did not use cerebrospinal fluid (CSF) drainage.

After systemic heparinization, a pigtail catheter was placed in the descending aorta under transesophageal echocardiography control and through a $6 \mathrm{~F}$ sheath in the femoral artery.

Arterial cannulation was performed directly or with an $8 \mathrm{~mm}$ dacron graft interposition to the target artery. According to the anatomy and pathology, axillary, innominate or carotid arteries were used in order to obtain antegrade flow in the thoracic aorta and to facilitate the brain protection during circulatory arrest. In highrisk reoperated patients, cardiopulmonary bypass (CPB) was started before performing the sternotomy.

The operation was carried out under moderate hypothermia $\left(20^{\circ} \mathrm{C}-28^{\circ} \mathrm{C}\right)$. Blood cardioplegia or crystalloid Bretschneider's solution (Custodiol, Dr. Franz Köhler Chemie GmBH, Alsbach-Hänlein, Germany) was delivered antegradely, retrogradely or combined. Once the heart was arrested, the aortic root or ascending aorta were repaired if needed. When the target temperature was achieved, circulatory arrest was instituted and antegrade selective cerebral perfusion was initiated. Aortic arch was resected, and distal aorta tailored to place the prosthesis.

The E-vita was placed antegradely. The prosthesis was inserted with a though-and-through wire technique with a 0.035 " extra stiff guidewire, that was introduced retrogradely through the pigtail catheter. Although the landing zone depended upon the extension of the disease, we changed the distal anastomosis site to zone 2 or more proximally over time. Graft size was chosen according to the etiology: 10-20\% oversizing in aneurysms and no oversizing in acute and chronic dissection.

Brain protection was achieved with unilateral or bilateral selective antegrade perfusion (SACP), and flow was adjusted to $10-15 \mathrm{~mL} / \mathrm{Kg} / \mathrm{min}$ and $50-60 \mathrm{mmHg}$ pressure. In order to improve the protection of the brain and spinal cord, we modified our technique to 1) perfuse the left subclavian artery (LSA) during lower body circulatory arrest and 2) early re- perfuse the thoracoabdominal aorta after the distal anastomosis was completed (Figure 2). LSA was dissected and ligated proximally during cooling. Its distal aspect was connected to the arterial line with an $8 \mathrm{~mm}$ dacron graft, which posteriorly, was anastomosed to the ascending aorta graft during rewarming. If supra-aortic arteries had to be re-implanted through a trifurcated graft, a femoral artery was also cannulated, and distal anastomosis were performed sequentially from the innominate artery to the LSA during cooling. The hybrid prosthesis was anastomosed to the distal remanent of the aorta with a double layer 3/0 polypropylene running suture and an external polytetrafluoroethylene felt.

Once the distal anastomosis was finished, a balloon catheter (Reliant, Medtronic, Mn, United States) was inserted antegradely to occlude the stent graft. Then, the blood flow in the thoracoabdominal aorta was resumed through the femoral artery and rewarming was started. If femoral cannulation had not been performed because of peripheral vascular disease or extensive dissection affecting the femoral arteries, a Foley catheter was used to occlude the stent graft and to perfuse the distal aorta. Then, supra-aortic arteries were implanted to the vascular graft, using three different techniques depending on the anatomy and pathology: en-block, en-block (IA, LCA) and LSA bypass or through a self-made trifurcated graft. We systematically avoid clamping the arch graft, but rather maintain the balloon catheter into the stent graft until the arch graft is anastomosed to the ascending aorta with a $4 / 0$ polypropylene running suture. In this way, it is easier to size the length of the arch prosthesis.

Follow-up 
Discharged patients were examined at the outpatient clinics after one, three and 6 months, and yearly thereafter. Computed tomography (CT) scans were performed at discharge, at three months and yearly.

Statistical analysis

SPSS 25.0 statistical package (IBM Corp, Armonk, NK, USA ) was used. Saphiro-Wilk test was used to test normality. Continuous variables were presented with mean \pm standard deviation (SD) or median and interquartile range (IQR). Categorical variables were presented in absolute and relative frequency. Two-side unpaired t-test andFischer's-exact test were used for comparison of continuous and categorical variables, respectively. Kaplan-Meier analysis was used for survival analysis.

\section{Results}

\section{In-hospital stay}

Intraoperative results are presented in Table 2. The right axillary artery is the most frequent artery for cannulation $(\mathrm{n}=33,58.9 \%)$. Brain protection was achieved with bilateral perfusion in most of the patients $(\mathrm{n}=47,83.9 \%)$. The E-vita Open prosthesis was deployed in Zone 2 in 42 cases $(75 \%)$. CPB, myocardial ischemia, SACP and lower body circulatory arrest times were $183 \pm 49 \mathrm{~min}, 109 \pm 40 \mathrm{~min}, 75 \pm 28 \mathrm{~min}$ and $42 \pm 18$ min, respectively.

As our experience grew (Figure 1) indications expanded and the technique evolved (Table 2). Thereby, main indications for surgery in group I were degenerative aneurysms $(56 \%, \mathrm{n}=14)$, and surgery was elective in $76 \%$ $(\mathrm{n}=19)$. On the contrary, in group II, the main indication for surgery was type A acute dissection $(45.2 \%$, $\mathrm{n}=14)$, and $48.8 \%(\mathrm{n}=15)$ of patients were operated on an urgent or emergent situation.

Regarding the technical modifications, in group II as compared to group I, brain protection was achieved under bilateral selective antegrade perfusion $(100 \%$ vs $64 \%, \mathrm{p}<0.001)$, distal anastomosis was moved to Z0-Z2 (100\% vs $72 \%, \mathrm{p}=0.02$ ), core temperature was higher $(25 \pm 2$ vs $22 \pm 3, \mathrm{p}<0.001)$, LSA was perfused during lower body circulatory arrest $(87.1 \%$ vs $0 \%, \mathrm{p}<0.001)$ and thoracoabdominal aorta perfusion was reestablished after distal anastomosis $(96.8 \%$ vs $40 \%, \mathrm{p}<0.001)$. These modifications resulted in a significant reduction of the lower body circulatory arrest time $(33 \pm 1 \mathrm{~min}$ vs $54 \pm 2 \mathrm{~min}, \mathrm{p}<0.001)$. Other modifications included arterial cannulation with graft interposition in almost any patient ( $96.8 \%$ vs $36 \%$, $\mathrm{p}<0.001)$, innominate artery as our artery of choice for cannulation ( $48 \%$ vs $16 \%, \mathrm{p}=0.01)$ and crystalloid Bretschneider's solution for myocardial protection $(96.8 \%$ vs $36 \%, \mathrm{p}<0.001)$.

Hospital mortality was $7.1 \%(n=4)$ (Table 3$)$. Causes of death were intraoperative hemorrhage, stroke, sepsis and respiratory failure.

Permanent stroke and spinal cord injury occurred in $3.6 \%(\mathrm{n}=2)$ and $1.8 \%(\mathrm{n}=1)$ respectively. Laryngeal nerve lesion occurred in $3.6 \%(\mathrm{n}=2)$. Hospital mortality $(12 \%, \mathrm{n}=3$ vs $3.2 \%, \mathrm{n}=1 ; \mathrm{p}=0.31)$, permanent stroke $(3.6 \%$, $\mathrm{n}=2$ vs $0 \%, \mathrm{n}=0 ; \mathrm{p}=0.28)$, and laryngeal nerve lesion $(8 \%, \mathrm{n}=2$ vs $0 \%, \mathrm{n}=0 ; \mathrm{p}=0.1)$ were less frequent in Group II (Table 3). Median ICU and hospital stay were 4 days (IQR 3-13 days) and 15 days (IQR 10-34 days), respectively, with no differences between Group I and II.

\section{Follow-up}

No patient required unplanned intervention on distal aorta. Fifteen patients (26.8\%) underwent a scheduled second stage (Figure 3): 12 aneurysms extending to the distal portion of the descending aorta, 2 thoracoabdominal aorta aneurysms and 1 type A chronic aortic dissection. Thirteen patients were treated endovascularly (12 thoracic endovascular aortic repair -TEVAR- and 1 fenestrated/branched endovascular aneurysm repair), 1 patient underwent an open repair and 1 patient a hybrid approach (TEVAR extension of E-vita Open prosthesis and subsequently open repair of distal aorta).

Mid-term clinical follow-up was achieved for all the patients (mean follow up: $20.9 \pm 18$ months). One- and three-year overall survival was $90.7 \%$ and $80.7 \%$ (Figure 4). Three patients underwent a reintervention 
during the follow-up. Reasons were type Ib endoleak $(n=1)$, pseudoaneurysm of the supra-aortic arteries patch anastomosis $(\mathrm{n}=1)$ and a distal false lumen enlargement in a Type A chronic dissection.

In acute and chronic dissections, a follow-up CT scan at 3 months was available in 24/26 patients. No stent induced new entry was detected. Complete thrombosis at mid portion of the stent-grafted aortic segment was observed in $79.2 \%$ of patients $(87.5 \%$ in acute dissection and $62.5 \%$ in chronic dissection, $\mathrm{p}=0.2)$ and at its distal aspect in $50 \%$ ( $56.3 \%$ in acute dissection and $37.5 \%$ in chronic dissection, $\mathrm{p}=0.6)$. Distal to the stent graft, complete false lumen perfusion remained in $62.5 \%$ (50\% in acute dissection and $85.7 \%$ in chronic dissection, $\mathrm{p}=0.1$ ).

\section{Discussion}

Endovascular repair is the treatment of choice for aneurysms or dissections of the thoracic descending aorta. When the disease extends to the arch, endovascular treatment is not a good option in most cases ${ }^{7}$ and open repair is challenging. The development of hybrid prostheses and the FET procedure ${ }^{8-10}$ has simplified the surgical treatment of these pathologies, allowing either a single-stage open procedure, or facilitating an open or endovascular second stage ${ }^{11,12}$. In acute and chronic dissections FET stabilizes the true lumen, covers the reentry sites in proximal descending thoracic aorta and promotes false lumen thrombosis and aortic remodeling, reducing the risk of distal aorta rupture and reinterventions ${ }^{3-5}$.

Two different hybrid prosthesis are available in Europe: The E-vita Open (Jotec GmbH, Hechingen, Germany ) and the Thoraflex (Vascutek, Terumo, Inchinnan, UK ). The E-vita Open is the prosthesis of choice at our center. Its main advantage is the intussuscepted position of the arch prosthesis, which facilitates the distal anastomosis. On the contrary, the lack of a side branch requires additional maneuvers to establish early reperfusion.

Authors from Essen have reported the greatest experience with E-vita Open prosthesis. They operated on 307 patients from 2005 to 2018. In-hospital mortality was 13.4\%. Permanent cerebral and spinal cord deficit occurred in $7.2 \%$ and $2.9 \%$, respectively ${ }^{13}$. Freedom from reintervention (open or endovascular) in distal aorta was $73 \%$ at 8 years. In acute type A aortic dissections, the false lumen remained thrombosed or resolved completely along the stent-graft aortic segment in $90 \%$ of patients. Authors from Hannover and Bologna have published their combined experience in 437 patients from 2007 to 2017. Three different hybrid prosthesis were used: the Chavan-Haverich (Hannover, Germany ), the E-vita Open and the Thoraflex ${ }^{14}$. In-hospital mortality was $14.9 \%$. Permanent stroke and spinal cord injury rates were $10.8 \%$ and $5.5 \%$, respectively. $23.1 \%$ of patients required an additional procedure, open or endovascular, during follow-up.

Although our series is still short, results are similar to those centers with greater experience. In-hospital mortality, permanent stroke and spinal cord injury were $7.1 \%, 3.6 \%$ and $1.8 \%$, in spite of a high preoperative risk (type A acute dissections $32.1 \%$, urgent surgery $37.5 \%$ and previous cardiac surgery in $19.6 \%$ ). This is due in part to an adequate patient selection, a case-to-case procedure planning, a limited and consistent operating room team (surgeon, nursing, anesthesiology and perfusion) and the standardization of the procedure. In our opinion, FET procedure is more reproducible than standard surgery in complex thoracic aortic disease, enabling small groups like ours to have comparable outcomes to bigger centers.

Since 2013 surgical technique has evolved. We have moved the distal FET anastomosis to Zone 0-2, started to perfuse the LSA during lower body circulatory arrest and perfusion in the thoracoabdominal aorta is reestablished once distal anastomosis is performed. Tsagakis et al showed that the combination of Z2 anastomosis, LSA perfusion and early reperfusion reduced the risk of postoperative renal replacement therapy, prolonged intubation, re-exploration for bleeding and laryngeal nerve lesion ${ }^{13}$. In our series in-hospital mortality and permanent stroke were reduced to $3.2 \%$ and $0 \%$ in the last two years (group II), respectively. This is probably related not only to the technique improvement but also to the greater experience. Z0, 1 o 2 anastomosis is less technically demanding. In addition, it is easier to reach in case of bleeding, reduces the risk of laryngeal nerve injury and avoids left pleural cavity opening.

We switched to bilateral antegrade cerebral perfusion because it is an easy maneuver which warrants an 
adequate perfusion of both hemispheres ${ }^{15}$. Although a very low stroke rate has been published with unilateral perfusion ${ }^{16}$, concern remains when the duration of selective perfusion is more than 50 minutes ${ }^{17}$.

$\mathrm{Z} 2$ anastomosis is combined with debranching of the LSA with an 8-mm dacron graft or all three supra-aortic arteries with a trifurcated graft during cooling. In this way, FET procedure is performed under perfusion of all supra-aortic arteries, improving cerebral and spinal cord perfusion during lower body circulatory arrest. To date, we have been able to dissect the LSA during cooling in all cases. When anatomy is unfavorable with a displaced LSA origin, an extension of the sternotomy incision to the left neck is done in order to get a wide left carotid artery dissection and mobilization. Alternatively, an extra-anatomic bypass to axillary artery through second intercostal space can be performed ${ }^{3}$.

Other improvements in our surgical technique were the interposition of a graft for arterial cannulation and the use of crystalloid Bretschneider's solution for myocardial protection. First, the innominate artery became our first-choice artery for cannulation, as additional incisions are not required, and it is easy to access. In addition, an $8 \mathrm{~mm}$ dacron graft is now systematically interposed to diminish the risk of retrograde dissection and improve distal perfusion ${ }^{18}$. Secondly, due to the complexity of this procedure, optimal myocardial protection plays a key role in achieving a successful outcome. Crystalloid Bretschneider's cardioplegia allows a prolonged myocardial protection in a single dose ${ }^{19}$. Finally,

The growing experience and the shorter lower body circulatory arrest time (Group I 54 \pm 20 min versus Group II $33 \pm 10 \mathrm{~min}, \mathrm{p}<0.001$ ) made it possible to raise nasopharyngeal temperature (Group I $22 \pm 3^{\circ} \mathrm{C}$ vs Group II $\left.25 \pm 3{ }^{\circ} \mathrm{C}\right)$. Length of stent graft was significantly shorter in Group II (135.5 $\pm 5 \mathrm{~mm}$ versus $150 \pm 9 \mathrm{~mm}$ ), which is explained because acute dissections are more frequent in this group (45.2\% versus 16\%). In acute aortic dissections, shorter stent grafts $(130 \mathrm{~mm})$ are enough to cover the reentry sites in proximal descending thoracic aorta and promote false lumen thrombosis.

We must not forget that FET is a major surgery which combines prolonged time on CPB, hypothermic circulatory arrest and is frequently performed in high risk patients, so it is not exempted of significant complications $^{3-5,13,14}$. Permanent stroke and specially spinal cord ischemia are the most feared and devastating. In a recent meta-analysis, Preventza et al analyze the pooled outcome of 3154 patients from thirty-five studies who underwent a FET procedure. In-hospital mortality was $8.8 \%$, and permanent stroke and spinal cord injury (SCI) rates were $7.6 \%$ and $4.7 \%$, respectively. Stent length of $15 \mathrm{~cm}$ or greater and coverage extending to T8 were associated with a higher risk of spinal cord ischemia. The proposed mechanism is the compromise of collateral flow from segmental arteries. Although its role is unquestioned, there must be other factors involved, because the incidence of SCI in endovascular treatment of thoracic aorta has a significant lower rate ${ }^{21}$. During open surgery, a period of spinal cord ischemia occurs during circulatory arrest. During SACP spinal cord is not perfused below T8-T9 and protection depends primarily on temperature ${ }^{22}$. On this basis, spinal cord is at risk in FET procedures at moderate $\left(28^{\mathrm{O}}-32^{\mathrm{O}}\right)$ temperatures with long systemic circulatory arrest times $(>60 \mathrm{~min})$. A third factor is an inadequate spinal cord perfusion in the postoperative period. Spinal cord suffers an ischemic insult during circulatory arrest and several segmental arteries are occluded, so a period of systemic hypotension can trigger the $\mathrm{SCI}^{23}$. It is critical to maintain an adequate perfusion pressure during perioperative period, raising mean blood pressure over $70 \mathrm{mmHg}$. Spinal cord perfusion pressure can also be improved with the use of intraoperative CSF drainage ${ }^{24}$. Other factors involved in neurological injury are hypoxia, anemia, hyperglycemia and hyperthermia ${ }^{25}$.

Paraplegia occurred in one patient: a 67-year-old woman operated in an emergent situation because an acute type A aortic dissection. A 22x130mm E-vita Open prosthesis was implanted in zone 0. She was extubated after six hours without any neurological deficit. 24 hours after surgery she presented a sudden massive hemorrhage and sustained severe hypotension. She was transferred to the operating room and bleeding was controlled. When she was extubated, $48 \mathrm{~h}$ later, paraplegia was present. Magnetic resonance imaging showed ischemic damage at T8 level. Despite hemodynamic and metabolic optimization and CSF drainage, paraplegia was permanent. Due to her small size (155 cm in height) the stent graft covered thoracic aorta until T9. Our hypothesis is that although collateral flow compensated initially the occlusion of segmental arteries, hemorrhage and subsequent sustained hypotension triggered the ischemia. 
This study has several limitations. First, although data is collected prospectively, its analysis is retrospective. Second, it is a single center experience, which makes difficult to support the external validity of our results. Finally, the sample size is small. We have almost doubled the number of procedures since we started the FET program; but, still, the center volume is low as compared to others (Bologna, Essen or Hannover).

\section{Conclusions}

In conclusion, FET procedure using the E-vita Open hybrid prosthesis is safe and the treatment of choice in complex thoracic aorta disease involving the aortic arch. It makes feasible a single stage correction when the disease does not extend beyond the proximal descending thoracic aorta. Furthermore, it also promotes false lumen thrombosis in aortic dissections and facilitates subsequent procedures on the distal aorta by endovascular, open or hybrid approaches.

\section{Author contributions}

Luis C Maroto: Concept, Drafting article; Manuel Carnero: Drafting article, Data analysis; Javier Cobiella: Critical revision; Rosa Beltrao: Data collection; Enrique Villagrán: Data collection; Fernando Reguillo: Critical revision; Daniel Pérez: Critical revision, Other.

\section{References}

1. Kouchoukos NT. One-stage repair of extensive thoracic aortic disease. J Thorac Cardiovasc Surg 2010;140:S150-3.

2. Etz CD, Plestis KA, Kari FA et al. Staged repair of thoracic and thoracoabdominal aortic aneurysms using the elephant trunk technique: a consecutive series of 215 first stage and 120 complete repairs. Eur J Cardiothorac Surg 2008;34:605-14.

3. Jakob H, Dohle D, Benedik J et al. Long-term experience with the E-vita Open hybrid graft in complex thoracic aortic disease. Eur J Cardiothorac Surg 2017;51:329-38.

4. Shrestha M, Martens A, Kaufeld T et al. Single-centre experience with the frozen elephant trunk technique in 251 patients over 15 years. Eur J Cardiothorac Surgery 2017;52:858-66.

5. Di Bartolomeo R, Pacini D, Savini C et al. Complex thoracic aortic disease: single-stage procedure with the frozen elephant trunk technique. J Thorac Cardiovasc Surg 2010;140(6 suppl):S81-5.

6. Abraha I, Romagnoli C, Montedori A, Cirocchi R. Thoracic stent graft versus surgery for thoracic aneurysm. Cochrane Database Syst Rev 2016;6:CD006796. doi:10.1002/14651858.CD006796.pub4.

7. Rudarakanchana N, Jenkins MP. Hybrid and endovascular repair of the aortic arch. Br J Surg 2018;105:315-27.

8. Kato M, Ohnishi K, Kaneko et al. New graft-implanting method for thoracic aortic aneurysm or dissection with a stented graft. Circulation 1996;94(9 Suppl)II188-II193.

9. Karck M, Chavan A, Khaladj N, Kallenbach K, Weidemann J, Haverich A. The frozen elephant trunk technique for the treatment of extensive thoracic aneurysms: Operative results and follow-up. Eur J Cardiothorac Surg 2005;28:286-290.

10. Jakob H, Tsagakis K, Leyh R, Buck T, Herold U. Development of an integrated stent graft-dacron prosthesis for intended one-stage repair in complex thoracic aortic disease. Herz 2005;30:766-68.

11. Uchida N, Kodama H, Katayama K et al. Endovascular aortic repair as second-stage surgery after hybrid open arch repair by the frozen elephant trunk technique for extended thoracic aneurysm. Ann Thorac Cardiovasc Surg 2013;19:257-61.

12. Folkmann S, Weiss G, Pisarik H, Czerny M, Grabenwoger M. Thoracoabdominal aortic aneurysm repair after frozen elephant trunk procedure. Eur J Cardiothorac Surg 2015;47:115-9.

13. Tsagakis C, Jakob H. Which frozen elephant trunk offers the optimal solution? Reflections from Essen group. Sem Thoracic Surg 2019;31:679-85.

14. Leone A, Beckmann E, Aandreas M et al. Total aortic arch replacement with frozen elephant trunk technique: Results from two European institutes. J Thorac Cardiovasc Surg 2020;159:1201-11.

15. Olsson C, Thelin S. Regional cerebral saturation monitoring with near-infrared spectroscopy during selective antegrade cerebral perfusion: diagnostic performance and relationship to postoperative stroke. 
J Thorac Cardiovasc Surg 2006;131:371-9.

16. Urbanski PP, Lenos A, Zacher M, Diegeler A. Unilateral cerebral perfusion:right versus left. Eur J Cardiothorac Surg 2010;37:1332-6.

17. Krähenbühl ES, Clément M, Reineke D et al. Antegrade cerebral protection in thoracic aortic surgery: lessons from the past decade. Eur J Cardiothorac Surg 2010;38:46-51.

18. Svensson LG, Blackstone EH, Rajeswaran J et al. Does the arterial cannulation site for circulatory arrest influence stroke risk? Ann. Thorac Surg 2004;78:1274-84.

19. Viana FF, Shi WY, Hayward PA, Larobina ME, Liskaser F, Matalanis G. Custodiol versus blood cardioplegia in complex cardiac operations: an Australian experience. Eur J Cardiothorac Surg 2013;43:52631.

20. Preeventza O, Liao JL, Olive JK et al. Neurologic complications after frozen elephant trunk procedure: A meta-analysis of more than 3000 patients. J Thorac Cardiovasc Surg 2019 doi:10.1016/j.jtcvs.2019.10.031.[Epub ahead of print]

21. Katayama K, Uchida N, Katayama A et al. Multiple factors predict the risk of spinal cord injury after elephant trunk technique for extended thoracic aortic disease. Eur J Cardiothorac Surg 2015;47:616-20.

22. Etz CD, Luehr M, Kari FA et al. Selective cerebral perfusion at $28^{\circ}$ C. Is the spinal cord safe? Eur J Cardiothorac Surg 2009;36:946-55.

23. Ullery BW, Cheung AT, Fairman RM et al. Risk factors, outcomes, and clinical manifestations of spinal cord ischemia following thoracic endovascular aortic repair. J Vasc Surg 2011;54:677-84.

24. Coselli JS, LeMaire SA, Koksoy C, Schmittling ZC, Curling PE. Cerebrospinal fluid drainage reduces paraplegia after thoracoabdominal aortic aneurysm repair: results of a randomized clinical trial. J Vasc Surg 2002;35:631-9.

25. Shann KG, Likosky DS, Murkin JM et al. An evidence-based review of the practice of cardiopulmonary bypass in adults: a focus on neurologic injury, glycemic control, hemodilution, and the inflammatory response. J Thorac Cardiovasc Surg 2006;132:283-90.

Table 1: Demographics

\begin{tabular}{|c|c|c|c|c|}
\hline & $\begin{array}{l}\text { Overall }(n=56) N \\
(\%)\end{array}$ & $\begin{array}{l}\text { Group } I(n=25) \\
N(\%)\end{array}$ & $\begin{array}{l}\text { Group II }(\mathrm{n}=31) \\
\mathbf{N}(\%)\end{array}$ & $\mathbf{p}$ \\
\hline Age $($ mean \pm SD $)$ & $63 \pm 12.1$ & $63.6 \pm 15$ & $63.5 \pm 9.3$ & 0.9 \\
\hline Male & $37(66)$ & $17(68)$ & $20(64.5)$ & 0.7 \\
\hline \multicolumn{5}{|l|}{ Etiology } \\
\hline Aneurysm & $27(48.2)$ & $14(56)$ & $13(41.9)$ & 0.42 \\
\hline Acute dissection & $18(32.1)$ & $4(16)$ & $14(45.2)$ & 0.02 \\
\hline $\begin{array}{l}\text { Chronic } \\
\text { dissection }\end{array}$ & $8(14.3)$ & $5(20)$ & $3(9.7)$ & 0.44 \\
\hline $\begin{array}{l}\text { TEVAR } \\
\text { complications }\end{array}$ & $2(3.6)$ & $1(4 \%)$ & $1(3.2)$ & 1 \\
\hline $\begin{array}{l}\text { Aortitis } \\
\text { Extent of aortic } \\
\text { disease }\end{array}$ & $1(1.8)$ & $1(4)$ & $0(0)$ & 0.44 \\
\hline $\begin{array}{l}\text { Arch }+ \text { descending } \\
\text { aor- }\end{array}$ & $23(41.1)$ & $11(44)$ & $12(38.7)$ & 0.32 \\
\hline $\begin{array}{l}t a( \pm \text { ascending }) \\
\text { Arch }+ \text { thoracoabdomin } \\
\text { aor- }\end{array}$ & $a \mathbb{2} 8(50)$ & $10(40)$ & $18(58.1)$ & 0.25 \\
\hline $\begin{array}{l}\text { ta }( \pm \text { ascending }) \\
\text { Isolated } \\
\text { descending aorta }\end{array}$ & $5(8.9)$ & $4(16)$ & $1(3.2)$ & 0.3 \\
\hline Emergency $(<24 \mathrm{~h})$ & $21(37.5)$ & $6(24)$ & $15(48.4)$ & 0.09 \\
\hline
\end{tabular}




\begin{tabular}{|c|c|c|c|c|}
\hline & $\begin{array}{l}\text { Overall }(n=56) N \\
(\%)\end{array}$ & $\begin{array}{l}\text { Group } I(n=25) \\
N(\%)\end{array}$ & $\begin{array}{l}\text { Group II }(\mathrm{n}=31) \\
\mathrm{N}(\%)\end{array}$ & $\mathbf{p}$ \\
\hline $\begin{array}{l}\text { Previous surgery } \\
\text { (ascending aorta } \\
\text { or arch) }\end{array}$ & 11(19.6) & $5(20)$ & $6(31)$ & 0.51 \\
\hline $\begin{array}{l}\text { Previous } \\
\text { descending aorta } \\
\text { repair }\end{array}$ & $5(8.9)$ & $2(8)$ & $3(9.7)$ & 0.91 \\
\hline $\begin{array}{l}\text { Previous } \\
\text { abdominal aortic } \\
\text { repair }\end{array}$ & $4(7.1)$ & $4(16)$ & $0(0)$ & 0.03 \\
\hline $\begin{array}{l}\text { Cardiac } \\
\text { comorbidities }\end{array}$ & & & & \\
\hline $\begin{array}{l}\text { Coronary artery } \\
\text { disease }\end{array}$ & $9(16.1)$ & $6(24)$ & $3(9.7)$ & 0.14 \\
\hline $\begin{array}{l}\text { Aortic valve } \\
\text { disease }\end{array}$ & $20(35.7)$ & $7(28)$ & $13(41.9)$ & 0.27 \\
\hline $\begin{array}{l}\text { Mitral valve } \\
\text { disease }\end{array}$ & $1(1.8)$ & $0(0)$ & $1(3.2)$ & 0.36 \\
\hline $\begin{array}{l}E F<50 \% \\
\text { Other } \\
\text { comorbidities }\end{array}$ & $1(1.8)$ & $0(0)$ & $1(3.2)$ & 0.36 \\
\hline Diabetes & $7(12.5)$ & $5(20)$ & $1(3.2)$ & 0.09 \\
\hline$C P O D$ & $13(23.2)$ & $7(28)$ & $6(19.4)$ & 0.44 \\
\hline $\begin{array}{l}\text { Creatinine clear- } \\
\text { ance }<60 \mathrm{~mL} / \mathrm{min}\end{array}$ & $6(10.7)$ & $3(12)$ & $3(12)$ & 0.78 \\
\hline Stroke & $4(7.2)$ & $2(8)$ & $2(6.4)$ & 0.49 \\
\hline
\end{tabular}

CPOD: chronic pulmonary obstructive disease, TEVAR: thoracic endovascular aortic repair

Table 2: Intraoperative results

\begin{tabular}{lllll}
\hline & $\begin{array}{l}\text { Overall }(\mathbf{n}=\mathbf{5 6}) \mathbf{N} \\
(\mathbf{\%})\end{array}$ & $\begin{array}{l}\text { Group I }(\mathbf{n = 2 5}) \\
\mathbf{N}(\mathbf{\%})\end{array}$ & $\begin{array}{l}\text { Group II (n=31) } \\
\mathbf{N}(\mathbf{\%})\end{array}$ & $\mathbf{p}$ \\
\hline $\begin{array}{l}\text { Arterial } \\
\text { cannulation }\end{array}$ & & & $\mathbf{0 . 0 0 6}$ \\
$\begin{array}{l}\text { Right axillary } \\
\text { artery }\end{array}$ & $33(58.9)$ & $20(80)$ & $13(41.9)$ & $\mathbf{0 . 0 1 3}$ \\
$\begin{array}{l}\text { Innominate } \\
\text { artery }\end{array}$ & $19(33.9)$ & $4(16)$ & $15(48)$ & 0.29 \\
$\begin{array}{l}\text { Right carotid } \\
\text { artery }\end{array}$ & $2(3.6)$ & $0(0)$ & $2(6.5)$ & 0.87 \\
$\begin{array}{l}\text { Left carotid } \\
\text { artery }\end{array}$ & $2(3.6)$ & $1(4)$ & $1(3.2)$ & $<\mathbf{0 . 0 0 1}$ \\
$\begin{array}{l}\text { Graft } \\
\text { interposition }\end{array}$ & $39(69.9)$ & $9(36)$ & $30(96.8)$ & $<\mathbf{0 . 0 0 1}$ \\
$\begin{array}{l}\text { Body temperature } \\
\text { (mean } \pm \text { SD) }\end{array}$ & $23.8 \pm 3.4$ & $22 \pm 3.6$ & $25 \pm 2.8$ & \\
$\begin{array}{l}\text { Myocardial } \\
\text { protection }\end{array}$ & & & &
\end{tabular}




\begin{tabular}{|c|c|c|c|c|}
\hline & $\begin{array}{l}\text { Overall }(n=56) N \\
(\%)\end{array}$ & $\begin{array}{l}\text { Group I (n=25) } \\
\text { N (\%) }\end{array}$ & $\begin{array}{l}\text { Group II }(\mathrm{n}=31) \\
\mathrm{N}(\%)\end{array}$ & $\mathbf{p}$ \\
\hline Blood cardioplegia & $16(28.6)$ & $15(60)$ & $1(3.2)$ & $<0.001$ \\
\hline $\begin{array}{l}\text { Crystaloid } \\
\text { cardioplegia }\end{array}$ & $40(71.4)$ & $10(40)$ & $30(96.8)$ & $<0.001$ \\
\hline $\begin{array}{l}\text { Brain protection } \\
\text { Unilateral } \\
\text { antegrade } \\
\text { perfusion }\end{array}$ & $9(16.1)$ & $9(36)$ & $0(0)$ & $<0.001$ \\
\hline $\begin{array}{l}\text { Bilateral } \\
\text { antegrade } \\
\text { perfusion }\end{array}$ & $47(83.9)$ & $16(64)$ & $31(100)$ & $<0.001$ \\
\hline $\begin{array}{l}\text { LSA perfusión } \\
\text { during visceral } \\
\text { ischemia }\end{array}$ & $27(48.2)$ & $0(0)$ & $27(87.1)$ & $<0.001$ \\
\hline $\begin{array}{l}\text { Early reperfusion } \\
\text { Level of distal } \\
\text { anastomosis }\end{array}$ & $37(66.1)$ & $10(40)$ & $30(96.8)$ & $<0.001$ \\
\hline Z3 & $7(12.5)$ & $7(28)$ & $0(0)$ & 0.02 \\
\hline $\begin{array}{l}<Z 3 \\
\text { Head vessels } \\
\text { reimplantation }\end{array}$ & $49(87.5)$ & $18(72)$ & $31(100)$ & 0.02 \\
\hline En-block & $9(16.1)$ & $9(36)$ & $0(0)$ & $<0.001$ \\
\hline $\begin{array}{l}\text { En block } \\
(I A+L C A)+ \\
L S A \text { bypass }\end{array}$ & $32(57.1)$ & $11(44)$ & $21(67.7)$ & 0.07 \\
\hline $\begin{array}{l}\text { Self-made } \\
\text { trifurcated graft } \\
\text { Aortic root }\end{array}$ & $15(26.8)$ & $5(20)$ & $10(32.3)$ & 0.3 \\
\hline $\begin{array}{l}\text { Bentall-De Bono } \\
\text { operation }\end{array}$ & $9(16.1)$ & $2(8)$ & $7(22.6)$ & 0.14 \\
\hline David operation & $3(5.4)$ & $2(8)$ & $1(3.2)$ & 0.43 \\
\hline $\begin{array}{l}\text { Partial repair } \\
\text { Evita-open size } \\
(\text { mean } \pm \mathrm{SD})\end{array}$ & $13(23.3)$ & $3(12)$ & $10(32.2)$ & 0.01 \\
\hline Diameter (mm) & $29 \pm 4.7$ & $29 \pm 4.1$ & 29.15 .4 & 0. \\
\hline $\begin{array}{l}\text { Length }(\mathrm{mm}) \\
\text { Concomitant } \\
\text { procedures }\end{array}$ & $142 \pm 12$ & $150 \pm 8.6$ & $135.5 \pm 11.5$ & $<0.001$ \\
\hline $\begin{array}{l}\text { Mitral valve } \\
\text { repair }\end{array}$ & $1(1.8 \%)$ & $0(0)$ & $1(3.2)$ & 0.36 \\
\hline $\begin{array}{l}C A B G \\
\text { Operative times } \\
\text { (minutes, } \\
\text { mean } \pm \mathrm{SD} \text { ) }\end{array}$ & $8(14.3)$ & $5(20)$ & $3(9.7)$ & 0.39 \\
\hline$C P B$ & $183 \pm 49.6$ & $182 \pm 48$ & $184 \pm 51$ & 0.38 \\
\hline $\begin{array}{l}\text { Cardioplegic } \\
\text { arrest }\end{array}$ & $109.4 \pm 40.4$ & $107 \pm 42$ & $110 \pm 39$ & 0.26 \\
\hline $\begin{array}{l}\text { Selective cerebral } \\
\text { perfusion }\end{array}$ & $75.5 \pm 28.1$ & $75 \pm 32$ & $75 \pm 25$ & 0.48 \\
\hline
\end{tabular}




\begin{tabular}{lllll}
\hline & $\begin{array}{l}\text { Overall }(\mathbf{n}=\mathbf{5 6}) \\
(\mathbf{\%})\end{array}$ & $\begin{array}{l}\text { Group I (n=25) } \\
\mathbf{N}(\boldsymbol{\%})\end{array}$ & $\begin{array}{l}\text { Group II (n=31) } \\
\mathbf{N}(\mathbf{\%})\end{array}$ & $\mathbf{p}$ \\
\hline $\begin{array}{l}\text { Lower body } \\
\text { circulatory arrest }\end{array}$ & $42.7 \pm 18.4$ & $54 \pm 20$ & $33 \pm 10$ & $<\mathbf{0 . 0 0 1}$ \\
\hline
\end{tabular}

CABG: coronary artery bypass grafting, CPB: cardiopulmonary bypass, IA: innominate artery, LCA: left carotid artery, LSA: left subclavian artery.

Table 3. In-hospital morbidity and mortality

\begin{tabular}{|c|c|c|c|c|}
\hline & $\begin{array}{l}\text { Overall }(\mathrm{n}=56) \mathrm{N} \\
(\%)\end{array}$ & $\begin{array}{l}\text { Group } I(n=25) \\
\text { N }(\%)\end{array}$ & $\begin{array}{l}\text { Group } 2(n=31) \\
N(\%)\end{array}$ & $\mathbf{p}$ \\
\hline $\begin{array}{l}\text { In-hospital } \\
\text { mortality }\end{array}$ & $4(7.1)$ & $3(12)$ & $1(3.2)$ & 0.31 \\
\hline Permanent stroke & $2(3.6)$ & $2(8)$ & $0(0)$ & 0.28 \\
\hline Transient stroke & $2(3.6)$ & $1(4)$ & $1(3.2)$ & 0.18 \\
\hline Paraplegia & $1(1.8)$ & $0(0)$ & $1(3.2)$ & 0.43 \\
\hline Delirium & $6(10.7)$ & $2(8)$ & $4(12.9)$ & 0.69 \\
\hline $\begin{array}{l}\text { Laryngeal nerve } \\
\text { lesion }\end{array}$ & $2(3.6)$ & $2(8)$ & $0(0)$ & 0.1 \\
\hline $\begin{array}{l}\text { Mechanical } \\
\text { ventilation }>72 \mathrm{~h}\end{array}$ & $12(21.4)$ & $6(24)$ & $6(19.4)$ & 0.67 \\
\hline $\begin{array}{l}\text { Temporary renal } \\
\text { replacement }\end{array}$ & $3(5.4)$ & $1(4)$ & $2(6.5)$ & 0.68 \\
\hline $\begin{array}{l}\text { Reoperation for } \\
\text { bleeding }\end{array}$ & $6(10.7)$ & $2(8)$ & $4(12.9)$ & 0.68 \\
\hline
\end{tabular}

\section{Figure legends}

Figure 1: FET caseload per year.

Figure 2: CPB setup. A: CPB onset. B: Cooling. Left subclavian artery bypass and proximal repair. C: Hypothermic circulatory arrest. Brain perfusion. Distal anastomosis. D: Early reperfusion through right femoral artery, rewarming and head vessels reimplantation.

Figure 3: Thoracic aorta aneurysm. A: Preoperative. B: After E-vita Open. C: After endovascular extension.

Figure 4: Kaplan-Meier analysis for survival. 

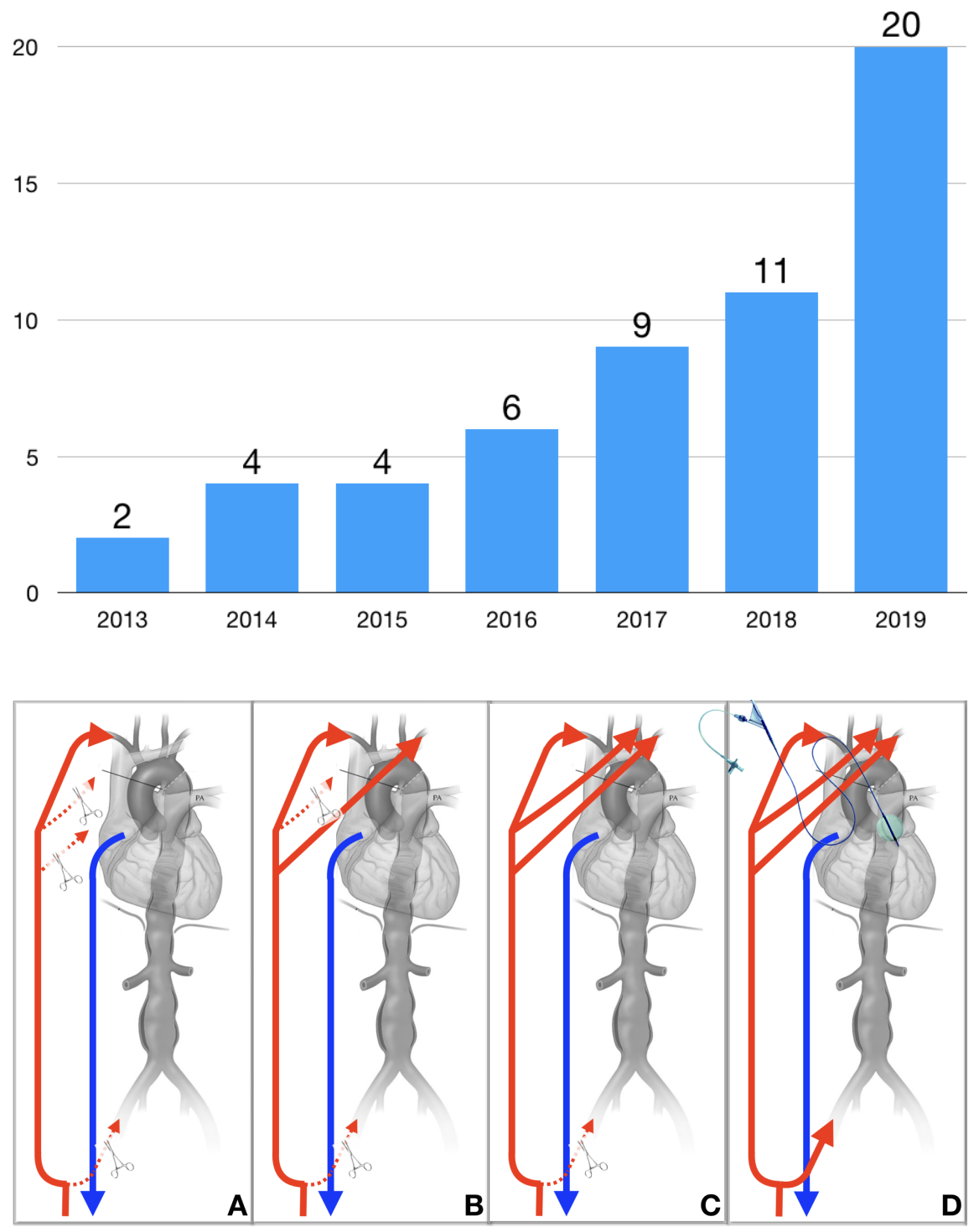

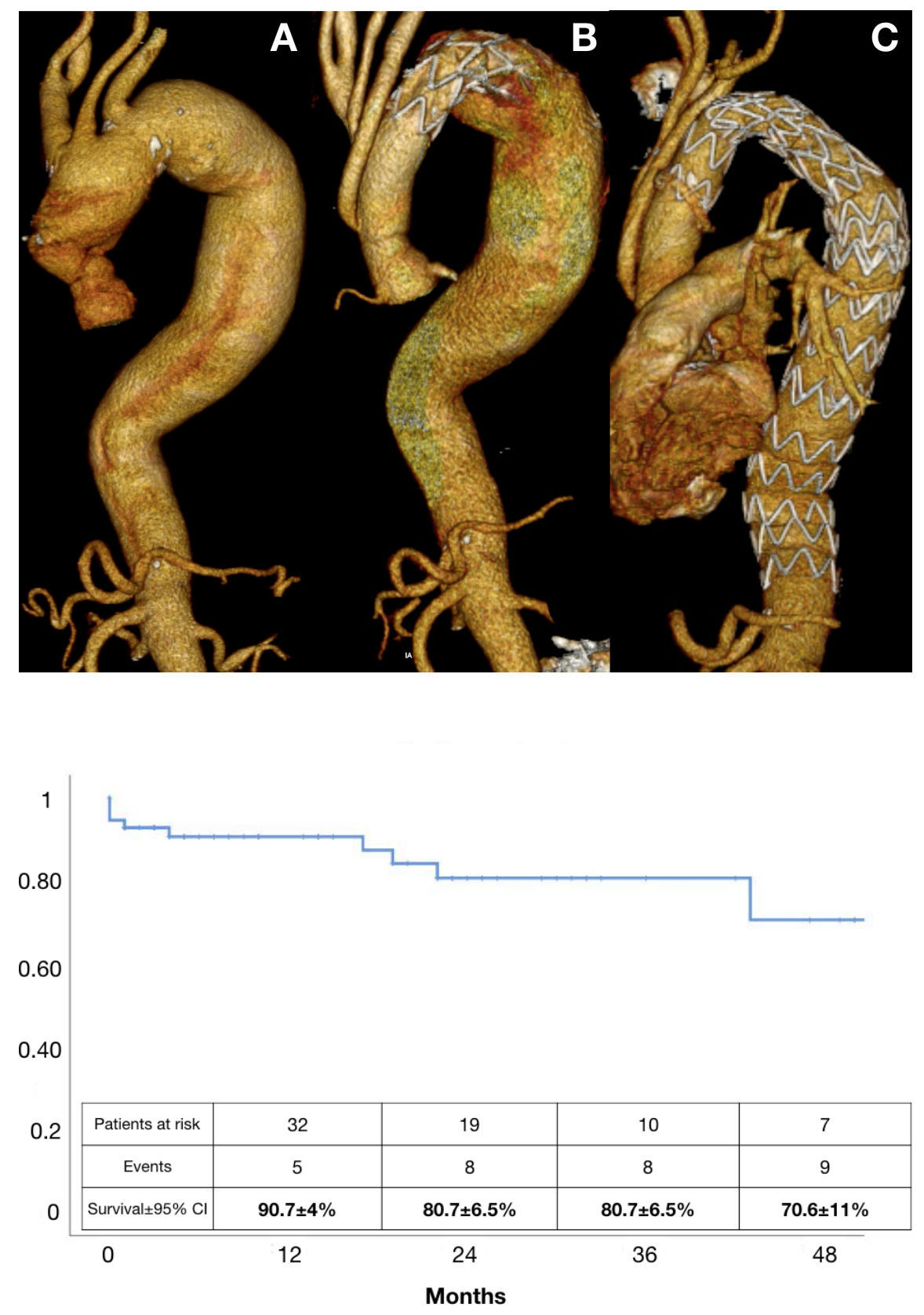